\title{
Mothers' Comfort with Screening Questions about Sensitive Issues, Including Domestic Violence
}

\author{
Therese Zink, MD, MPH, Linda Levin, PhD, Peter Wollan, PhD, and \\ Frank Putnam, MD
}

Purpose: To assess patient ratings of comfort alone and in front of children with 5 domestic violence (DV) screening questions designed with less graphic language compared with questions about other sensitive issues.

Methods: A sample of mothers $(\mathrm{n}=200)$, including a small sample of Spanish-speaking women, were recruited from community locations. Mothers rated their perceptions of comfort for answering 13 sensitive issue screening questions (including sexual risk, substance abuse, depression, and DV questions). Logistic regression was performed to analyze participants' characteristics with respect to summary comfort scores. In addition, $\mathbf{4 0}$ mothers were asked to talk about their comfort in answering the DV questions. These interviews were audiotaped and analyzed.

Results: Mothers preferred to answer all questions alone. Comfort with answering the DV screening questions in front of their children was higher than comfort with sexual risk or depression questions and was similar to comfort with substance abuse questions. Latina mothers had more discomfort with the DV questions than other ethnicities.

Conclusions: Although mothers were more comfortable with answering sensitive questions alone than in the presence of children, this may not be feasible in busy offices. General DV questions may be appropriate to ask in front of children as an initial screen. (J Am Board Fam Med 2006;19:358-67.)

Domestic violence (DV) affects the health of women and their children. ${ }^{1-5}$ Although current evidence does not support or refute the effectiveness of the universal screening for DV in the medical setting, ${ }^{6-8}$ professional organizations recommend identifying patients and sharing resources such as the numbers of local advocacy agencies. ${ }^{9-13}$ Identifying DV and helping patients understand the impact this stress has on their health and the health of their children is important for quality health care. ${ }^{14-18}$

A variety of DV screening questions and tools have been developed and validated. ${ }^{19-24}$ Women have reported discomfort with some of the more direct questions ${ }^{25}$ and graphic language such as hitting, kicking, or hurting is not appropriate in the presence of children. ${ }^{26,27}$ Physicians also report more comfort with more indirect questions about DV. ${ }^{25}$

Submitted 7 October 2005; revised 30 January 2006; accepted 1 February 2006.

From the Department of Research, Olmsted Medical Center, Rochester, MN (TZ, PW); and University of Cincinnati, OH (LL, FP).

Funding: The project was funded by a Robert Wood Johnson Generalist Faculty Scholar Award.

Conflict of interest: none declared.

Corresponding author: Therese Zink, MD, MPH, Department of Research, Olmsted Medical Center, 210 9th Street SE, Rochester MN 55992 (E-mail: zink0003@umn.edu).
Currently DV screening protocols recommend screening women alone (no partners or children). However, due to the logistics of removing children from the room in busy practices, screening may not occur if children must be removed. In response, some authors have developed more general DV screening questions that are thought to be less explicit and intrusive. ${ }^{23,25}$ To date, they have not been tested for comfort when women are with their children in the medical office. Similarly, they have not been compared with other socially sensitive medical topics that clinicians also ask about routinely such as sexual behavior or drug/alcohol use.

To address these knowledge deficits, we tested the theoretical comfort of 5 general DV screening questions that were identified as appropriate in front of children by mothers/victims ${ }^{27}$ and examined women's perceptions of comfort compared with questions about other sensitive health screening issues (sexual risk, alcohol/drug use, and depression).

\section{Methods \\ Participants and Recruitment}

Mothers with at least one child between 3 and 12 years of age were recruited to participate in a study 
about "screening for sensitive issues in the physician's office." Fliers were posted at schools, places of employment, churches, and local social service agencies. Locations were varied to engage a diverse (socioeconomic and race/ethnicity) pool of participants. To examine this issue for a growing Latino population, we worked with organizations serving Spanish-speaking clients to recruit a small Latina cohort. This cohort was diverse in country of origin, education level, and socioeconomic status. Participants either telephoned to schedule an appointment for the interview or completed the interview at the time of recruitment. Interviews occurred in a private room at a convenient location, such as a private room at the school, the community center, the church, or work.

\section{Instrument and Administration}

The University of Cincinnati Institutional Review Board approved the protocol. The instrument included 5 general DV questions identified as appropriate in front of children in our earlier work. ${ }^{27}$ Validated screening questions for other sensitive screening issues for alcohol, ${ }^{28}$ drug use, ${ }^{29}$ sexual practices, ${ }^{30,31}$ depression, ${ }^{32,33}$ and 2 more general questions about speeding tickets and shop lifting were selected. The topic areas were intermixed. Each question was followed by 2 questions about comfort: How comfortable are you answering this question in front of your children? How comfortable are you answering this question alone? Participants responded using a 5-point Likert scale from very uncomfortable to very comfortable. For the Latina cohort, the questionnaire and consent were translated into Spanish by a professional translator and then back translated to insure accuracy. Trained graduate students (male and female) conducted the interviews. The graduate student who performed the Latina interviews was bilingual.

The study was explained, and the consent reviewed in a private area. Sometimes mothers had their children with them $(<10 \%)$. If present, the children were given toys and books to occupy them and they did not interfere with the interview process. The research assistant presented each question verbally and visually on a 6 by 8 card. The participant was asked to answer the question and then to rate her comfort (alone and in front of her children). Then participants ranked the $5 \mathrm{DV}$ questions from most to least comfortable in front of the children. DV status was ascertained either by the participant spontaneously revealing her history or with a direct question: "Do you have any personal experience with domestic violence?" Local DV crisis agency pamphlets were offered to all participants. Participants received a \$20 honorarium.

For the qualitative portion of the study, the first 40 participants were asked an open-ended question, their responses were audiotaped, and notes taken. The question was: "Now we want your opinions on these questions. Which do you like the best, which do you like the least in front of your children?" Additional probes were asked as appropriate, such as, "Tell me what you like about this question," and "Tell me what you don't like." Due to the costs of translation and transcription, Latinas were not included in the 40 interviewed mothers. Despite this limitation, a range of diverse responses (theoretical saturation) was obtained. ${ }^{34}$

\section{Analysis \\ Quantitative}

Frequencies were calculated for demographic information, question responses, comfort scales, and the rank order of the general DV questions for the entire sample $(\mathrm{n}=200)$. Means, medians, and ranges of comfort (alone and with child) were obtained for all participants. Comfort levels for each question and each situation (mom alone and with child) were dichotomized separately. The response categories very comfortable (5) and somewhat comfortable (4) were considered as "comfortable." The percentages of comfortable (4-5) responses for alone and with child were tested with McNemar's statistic, a commonly used method for measuring equality of proportions between 2 groups of repeated outcomes on the same participant. ${ }^{35}$ Mean comfort levels for questions grouped by topic were compared using Wilcoxon signed-rank tests.

Questions related to DV were grouped, and any response other than "comfortable" on any of the 5 DV questions was used as an indication of potential discomfort. Logistic regression models were fit to evaluate the demographic variables as predictors of discomfort. The modeling of characteristics was based on the demographic factors known to be related to DV victimization. ${ }^{36,37}$. These included ethnicity/race (African American, Latina, White), income level (low $=$ at most $\$ 20,000$, medium $=$ above $\$ 20,000$ and at most $\$ 40,000$, high $=$ over $\$ 40,000$ ), education ( $\leq 12$ years, $>12$ years), DV experience either current or past (no/yes), current relationship 
(no/yes), and depression (no/yes). Statistical significance determined by $P$ values of statistical significance was denoted by values of $P \leq .05$.

\section{Qualitative}

Audiotaped discussions about comfort with the general DV questions and screening in front of children were transcribed verbatim. Two researchers with experience in qualitative methodology used an immersion/crystallization style to explore participants' responses to the questions and the screening process. In this interpretive style, each researcher read the transcripts independently and recorded his or her summary comments and possible themes. Over several sessions the researchers met to compare observations, review responses to each question and identify the major themes from the data. ${ }^{38}$ The themes were organized into the reasons for liking or disliking each general DV question and comments on the screening process, especially in front of the children. A third researcher examined the transcripts to check that the range of responses was captured. Disagreements were resolved by discussion until consensus was reached and checked by the third researcher.

\section{Results}

The median age of the mothers was 34 years (range 19 to 54$)$. The median number of children was 2.5 (range 1 to 6 ). More than three fourths were currently in a relationship (77\%), and $63 \%$ were married or had a steady partner. Almost half were white (47\%), 31\% African American, and 23\% Latina. More than one third (39\%) had current or past experience with an abusive intimate relationship. For demographic details see Table 1 . Because most of the participants contacted us, we had few refusals.

Table 2 shows comfort scores for each question and question category. Mothers reported significantly more comfort when alone than with child for all categories (general DV, sexual risk, substance abuse, depression, and speeding/shop lifting) $(P<$ .001). In addition, percentage of comfort when alone was significantly greater than with child for all individual questions $(P<.01)$. Mean comfort levels for the questions categories (DV, substance abuse, and speeding/shop lifting) were similar, although the largest differences among the 3 means attained statistical significance $(P=.03$ alone, $P=.01$ with child, not adjusted for multiple comparisons). Mean
Table 1. Demographic Characteristics of Participants $(\mathrm{n}=200)$

\begin{tabular}{lc}
\hline Characteristic & Mean (Range) \\
\hline Age in years & $34(19-54)$ \\
Number of children/mother & $2.5(1-6)$ \\
& Number \\
& (percentage of 200) \\
Currently pregnant & $7(4 \%)$ \\
Currently in a relationship & $154(77 \%)$ \\
Marital Status & \\
Single/divorced/widowed & $74(37 \%)$ \\
Married & $126(63 \%)$ \\
Current or past experience of & $78(39 \%)$ \\
intimate partner violence/abuse & \\
Ethnicity/Race & \\
White & $93(47 \%)$ \\
African American & $61(31 \%)$ \\
Latina & $46(23 \%)$ \\
Education & \\
$\leq 12$ th grade & $110(55 \%)$ \\
$>12$ th grade & $90(45 \%)$ \\
Income/year & \\
\$20,000 &
\end{tabular}

levels for depression and sexual risk were also similar, but the level of discomfort with the sexual risk questions with child was great enough for the difference to be highly significant $(P=.26$ alone, $P<$ .0001 with child). The gap between the means of the depression and sexual risk categories was significant for both alone and with child $(P=.003$ and $P<$ .0001 , respectively).

All mothers were asked to rank DV questions according to their comfort with the question when it was asked with the children present. The frequencies with which questions were ranked in either first or second place were as follows: Do you feel safe in your current relationship (31.8\%)? How is your partner treating you and the children $(22.5 \%)$ ? In general, how do you describe your relationship $(21.5 \%)$ ? How do you and your partner work out arguments (15\%)? Considering your current partners or friends or any past partners or friends is there anyone who is making you feel unsafe now (9.3\%)? Mothers with DV experience followed a similar pattern regarding comfort with the questions in front of children: safe $(30.8 \%)$, treating $(21.2 \%)$, describe $(21.2 \%)$, arguments $(16 \%)$, and unsafe (10.8\%). 
Table 2. Mean comfort response and percentage of comfort (very comfortable and somewhat comfortable responses) with children and alone, for each sensitive question by individual questions and question category

\begin{tabular}{|c|c|c|c|c|}
\hline Question & $\begin{array}{l}\text { With Child } \\
\text { Mean Comfort }\end{array}$ & $\begin{array}{c}\text { Alone } \\
\text { Mean Comfort }\end{array}$ & $\begin{array}{l}\text { With Child } \\
\text { Percentage of Comfort }\end{array}$ & $\begin{array}{c}\text { Alone } \\
\text { Percentage of Comfort }\end{array}$ \\
\hline General DV questions & 3.2 & 3.7 & 81.2 & 94.2 \\
\hline $\begin{array}{l}\text { Do you feel safe in your current } \\
\text { relationship? }\end{array}$ & 3.3 & 3.7 & 84.5 & 93.5 \\
\hline $\begin{array}{l}\text { In general how would you describe your } \\
\text { relationship? }\end{array}$ & 3.0 & 3.7 & 77.0 & 94.0 \\
\hline $\begin{array}{l}\text { How do you and your partner work out } \\
\text { arguments? }\end{array}$ & 3.1 & 3.7 & 76.5 & 92.5 \\
\hline $\begin{array}{l}\text { How is your partner treating you and } \\
\text { the kids? }\end{array}$ & 3.4 & 3.8 & 85.5 & 94.5 \\
\hline $\begin{array}{l}\text { Considering your current partners or } \\
\text { friends or any past partners or friends } \\
\text { is there anyone who is making you } \\
\text { feel unsafe now? }\end{array}$ & 3.3 & 3.8 & 81.5 & 96.5 \\
\hline Sexual risk questions & 2.2 & 3.6 & 52.0 & 85.0 \\
\hline $\begin{array}{l}\text { Have you had } 2 \text { or more sexual partners } \\
\text { in the past } 10 \text { years? }\end{array}$ & 2.0 & 3.5 & 50.5 & 89.0 \\
\hline $\begin{array}{l}\text { Have you ever had a sexually } \\
\text { transmitted disease such as gonorrhea, } \\
\text { syphilis, chlamydia, genital warts, or } \\
\text { genital herpes? }\end{array}$ & 2.3 & 3.6 & 45.5 & 90.0 \\
\hline Substance abuse questions & 3.3 & 3.8 & 83.2 & 95.7 \\
\hline $\begin{array}{l}\text { Have you injected street drugs, steroids, } \\
\text { or vitamins with a needle? }\end{array}$ & 3.5 & 3.8 & 87.0 & 96.5 \\
\hline $\begin{array}{l}\text { Have you used drugs for other than } \\
\text { those required for medical reasons? }\end{array}$ & 3.1 & 3.8 & 76.5 & 95.0 \\
\hline $\begin{array}{l}\text { How often do you have more than } 4 \\
\text { alcohol drinks in a day? }\end{array}$ & 3.4 & 3.8 & 86.0 & 95.5 \\
\hline Depression & 2.9 & 3.6 & 70.5 & 90.0 \\
\hline $\begin{array}{l}\text { In the past year, have you had } 2 \text { weeks } \\
\text { or more during which you felt sad, } \\
\text { blue or depressed or lost pleasure in } \\
\text { things that you usually cared about or } \\
\text { enjoyed? }\end{array}$ & 2.9 & 3.6 & 70.5 & 90.0 \\
\hline Speeding/shop lifting questions & 3.4 & 3.7 & 85.3 & 93.2 \\
\hline Have you had a speeding ticket? & 3.6 & 3.6 & 92.0 & 96.0 \\
\hline Have you ever shoplifted? & 3.2 & 3.8 & 78.5 & 90.5 \\
\hline
\end{tabular}

Participants were presented 2 questions: How comfortable are you answering this question in front of your children? How comfortable are you answering this question alone?

Responses options: very comfortable (5)/somewhat comfortable (4)/neither (3)/somewhat uncomfortable (2)/very uncomfortable (1). Median comfort was 4 for all questions except 'Sexual risk' questions (medians 2,3, respectively).

Percentage of comfort was significantly different for 'alone' and 'with child' in all question categories $(P<.001)$ and for all individual questions $(P<.01)$ using McNemar's statistic.

Table 3 shows results from the logistic regression analysis of comfort with the DV questions related to participants' characteristics. Race/ethnicity was consistently statistically significant as a predictor for discomfort, for the DV questions grouped together and with each of the DV questions separately, both with children and alone. Latinas consistently had more discomfort than other ethnic groups. Income level was marginally significant in some models, with higher income levels showing more discomfort, but results were not consistent. Likewise, education level was marginally significant in some models $(P<.10)$, with more education associated with less discomfort. Other variables tested showed no evidence of association.

\section{Qualitative Results}

The first 40 mothers that were also interviewed and audiotaped were more educated and had higher incomes than that of the entire sample $(n=200)$ : 
Table 3. Factors associated with discomfort on any of the domestic violence questions. Results from logistic regression.

\begin{tabular}{|c|c|c|c|}
\hline Characteristics & Categories & $\begin{array}{l}\text { Odds Ratio } \\
\text { (95\% CI) }\end{array}$ & $P$ Value \\
\hline \multirow{9}{*}{$\begin{array}{l}\text { Ethnicity } \\
\text { (Compared with White as baseline) }\end{array}$} & $\underline{\text { Latina }}$ & & \\
\hline & Alone & $4.84(1.78,13.19)$ & .002 \\
\hline & With child & $2.53(1.22,5.24)$ & .01 \\
\hline & $\underline{\text { African American }}$ & & \\
\hline & Alone & $0.86(0.24,3.08)$ & .82 \\
\hline & With child & $0.63(0.31,1.27)$ & .19 \\
\hline & $\underline{\text { African American }}$ & & \\
\hline & Alone & $0.86(0.24,3.08)$ & .82 \\
\hline & With child & $0.63(0.31,1.27)$ & .19 \\
\hline \multirow[t]{3}{*}{ Income } & High $(>\$ 40,000)$ & & \\
\hline & Alone & $0.76(0.25,2.28)$ & .62 \\
\hline & With child & $0.78(0.37,1.63)$ & .50 \\
\hline \multirow[t]{3}{*}{ (Compared to low ( $>\$ 20,000$ as baseline) } & Medium $(\$ 20,000$ to $\$ 40,000)$ & & \\
\hline & Alone & $0.65(0.23,1.82)$ & .41 \\
\hline & With child & $0.92(0.48,1.77)$ & .80 \\
\hline \multirow[t]{3}{*}{ Education } & $\geq 12$ th grade & & \\
\hline & Alone & $2.19(0.87,5.55)$ & .10 \\
\hline & With child & $0.80(0.45,1.41)$ & .44 \\
\hline \multirow[t]{3}{*}{ Current relationship } & $\underline{\text { Yes }}$ & & \\
\hline & Alone & $0.88(0.33,2.37)$ & .80 \\
\hline & With child & $1.06(0.54,2.08)$ & .87 \\
\hline \multirow[t]{3}{*}{ DV experience } & $\underline{\text { Yes }}$ & & \\
\hline & Alone & $1.08(0.44,2.60)$ & .87 \\
\hline & With child & $1.10(0.61,1.98)$ & .75 \\
\hline
\end{tabular}

$72 \%$ with $>12$ years of education compared with $45 \%$ in the entire sample; $77 \%$ with income $\geq \$ 20,000$ compared with $53 \%$, and $23 \%$ with DV experience compared with $39 \%$. Otherwise age, race/ethnicity, and marital status were similar. Feedback on the 5 questions was both positive and negative and focused on the wording of the questions, the type of answer it might elicit, and the potential consequence of the questions. Results are listed in Table 4.

In addition, mothers shared their thoughts about child-centered approaches to asking, the process of screening, how clinicians should deal with the responses, and issues around disclosing DV. Examples of each theme are presented and discussed.

\section{Child-centered Approaches to Screening}

As a former victim I would have had not very good answers, but they would have been truthful answers. I think they are excellent questions to ask somebody rather than flat out saying - are you being abused, especially in front of the children?
Someone can talk in code or give at least enough verbiage in an answer that the physician or nurse ... there is more to this, we need to discuss this further.

Physicians should not ask about the details [of DV] in front of the children.

Even in the qualitative data, it was clear that mothers preferred to be screened about DV without their children, but as stated above, these questions with less graphic language gave mothers the leeway to indicate that something was not right, "there is more to this," so that clinicians could create privacy for further discussion. Both mothers with and without DV experience expressed these thoughts.

Both the age of the children and relating DV screening to the health of the child were important factors.

It depends on the kid, like my 8 year old, she's a worrier.

Like my 5 year old, I would feel comfortable cause I don't think they would know what I was talking about, but my 9 year old obviously would. 
Table 4. Typical quotes from mothers $(n=40)$ about general DV questions

\begin{tabular}{|c|c|c|}
\hline Question & Positive & Negative \\
\hline \multirow[t]{4}{*}{$\begin{array}{l}\text { How do you and your partner work } \\
\text { out arguments? }\end{array}$} & $\begin{array}{l}\text { I can be euphemistic and give coded } \\
\text { answers. }\end{array}$ & $\begin{array}{l}\text { Use disagreement instead of argument, } \\
\text { kids might be embarrassed by the } \\
\text { answer. }\end{array}$ \\
\hline & $\begin{array}{l}\text { Gives the physician an idea about how } \\
\text { problems are solved. }\end{array}$ & \\
\hline & & $\begin{array}{l}\text { One day it might be terrible and } 3 \text { days } \\
\text { later it might be fine, but it's not } \\
\text { necessarily abuse. }\end{array}$ \\
\hline & & $\begin{array}{l}\text { Seems intrusive } \ldots \text { is that any of your } \\
\text { business? }\end{array}$ \\
\hline \multirow[t]{3}{*}{$\begin{array}{l}\text { In general how do you describe your } \\
\text { relationship? }\end{array}$} & $\begin{array}{l}\text { No trigger words; opens the door to } \\
\text { learning more. }\end{array}$ & $\begin{array}{l}\text { Your relationship should not be } \\
\text { discussed in front of the kids. }\end{array}$ \\
\hline & & $\begin{array}{l}\text { Too general to find out about domestic } \\
\text { violence. }\end{array}$ \\
\hline & $\begin{array}{l}\text { There are a lot of euphemisms you can } \\
\text { use to describe a relationship that's not } \\
\text { going well. }\end{array}$ & You can't give one-word answers. \\
\hline \multirow[t]{4}{*}{$\begin{array}{l}\text { How is your partner treating you and } \\
\text { the kids? }\end{array}$} & $\begin{array}{l}\text { For domestic violence this would be the } \\
\text { true question. }\end{array}$ & $\begin{array}{l}\text { What does that mean? Like does he buy } \\
\text { me a diamond ... }\end{array}$ \\
\hline & Good way to open up. & Like is he a good provider? \\
\hline & $\begin{array}{l}\text { We're a package, if you like me you've } \\
\text { got to like my kids. }\end{array}$ & Separate the you and kids. \\
\hline & This gets at child abuse. & Seems too nosey, too straightforward. \\
\hline \multirow[t]{3}{*}{$\begin{array}{l}\text { Do you feel safe in your current } \\
\text { relationship? }\end{array}$} & It's all about safety. & $\begin{array}{l}\text { Safe is a red flag in our house. It's } \\
\text { mommy's job to keep you safe. }\end{array}$ \\
\hline & $\begin{array}{l}\text { Can just give a one-word answer-yes or } \\
\text { no. }\end{array}$ & $\begin{array}{l}\text { Kids will understand safe, maybe stable } \\
\text { or secure Perhaps stressed instead of } \\
\text { safe... }\end{array}$ \\
\hline & $\begin{array}{l}\text { Good question, it is the follow-up that } \\
\text { might cause problems. }\end{array}$ & $\begin{array}{l}\text { Safety, that's admitting vulnerability. } \\
\text { There may even be some pride } \\
\text { involved. }\end{array}$ \\
\hline \multirow{3}{*}{$\begin{array}{l}\text { Considering your current partners or } \\
\text { friends or any past partners or } \\
\text { friends, is there anyone who is } \\
\text { making you feel unsafe now? }\end{array}$} & $\begin{array}{l}\text { Can admit something wrong without } \\
\text { having to say exactly. }\end{array}$ & Too vague \\
\hline & So convoluted, kids won't understand. & Kids understand safe and unsafe. \\
\hline & $\begin{array}{l}\text { If you are not in a current relationship } \\
\text { you still could have a past person that is } \\
\text { causing problems. }\end{array}$ & $\begin{array}{l}\text { Instead of partners and friends, say } \\
\text { people. You know how kids think ... } \\
\text { it depends on how a parent introduces } \\
\text { their kids to people they date. It } \\
\text { might be somebody the kid didn't like }\end{array}$ \\
\hline
\end{tabular}

Relate it (screening for DV) back to belping the kid as opposed to prying questions .... it's a child's medical issue, not a stand alone matter . . interlace them, your child has asthma, it is worse with physical exercise, but it can be worse with stress or tension. You got to tie it back into what it means to me and there's [nothing] nearer and dearer to my heart then something about my kids.

Again, children who are old enough to understand a discussion about DV were a concern, and mothers recommended that detailed discussions and resource sharing be done in private. Giving some context to the reason for inquiring about DV was also important; DV can affect the child's health. In the final quote, the mother, a DV victim, reminds us of the importance of the children. The children may be a leverage point. A mother may take steps for the benefit of her children that she may not take for herself, such as asking for assistance to decrease the stress on her children or to improve their safety.

\section{The Screening Process}

Mothers encouraged clinicians to move from general to specific, and to ask in a conversational manner.

If the doctor can be more friendly and conversational I think the person is more likely to feel safe in talking... create a flow, how is the relationship with you and your busband? Are you guys okay, do you work out arguments fairly well? Are the kids being treated okay? . . more conversational rather than okay, the first question is ... 
Don't ask the same question every time, it's like ob yeah that question again. But if you kind of phrase things differently ... you might open the door in a different way.

Talk to the person in their manner of speaking or phrasing . . . a certain colloquialism . . . be familiar with the person.

Normalizing and phrasing DV screening questions in a manner that was conversational and tailored to the understanding and needs of the mother were important points.

\section{Mothers Emphasized the Importance of Clinicians' Responses}

[Physicians should read] any hesitancy as a red flag [for $D V]$... facial expressions or mannerisms may say that we need to talk about this.

A mother's heart will open up toward what can I do [about DV] when you relate [it] back to helping their kid in that situation. ... Why this [DV] is important, [the physician should] interlace [the DV] back to the child.

Many mothers stressed the importance of picking up on clues and hints that there was more to discuss or that privacy was needed. In addition, several mothers talked about the importance of educating mothers about how DV affects the child. Clinicians were also encouraged to know the local DV resources to have DV materials available that mothers could pick up discreetly.

\section{Issues Surrounding Disclosure}

What I share depends on how the relationship is going.

Mothers who had dealt with DV were open to having the children understand the importance of these questions and knowing how to be safe. "My child should know how to call 911." Others who were still working through an abusive relationship were more cautious about what they wanted to share and admitted that they might not disclose the $\mathrm{DV}$, as suggested in the above quote. However, mothers with and without a history of DV clearly stated that they thought these questions were important and that they would open the door for sharing in the future.

\section{Discussion}

Mothers had more comfort with general DV screening questions in the presence of their children than with questions about depression and sexual risk. Comfort with the DV questions was sim- ilar to comfort with the substance abuse screening items. Latina mothers had significantly more discomfort about DV screening questions. Mothers with DV experience had similar levels of comfort to those with no DV experience. The implications of these findings are discussed.

Mothers preferred to be alone for all sensitive screening questions. The high rates of comfort alone ( $\geq 94 \%)$ and in front of the children $(\geq 76 \%)$ should address clinicians' concerns about offending patients with DV screening. ${ }^{25}$ Clinicians routinely inquire about many personal issues both alone and in the presence of the children, and our findings show that the general DV questions had no greater discomfort than the other sensitive areas. Questions about sexual risk and depression created the most discomfort.

Regarding sexual risk, both stigma and embarrassment affects patients' health care seeking behavior. ${ }^{39,40}$ Depression can also be shrouded with the stigma of mental illness. ${ }^{41}$ In a study that examined mothers' willingness to discuss parenting stress and depressive symptoms with their child's pediatrician, Heneghan et $\mathrm{al}^{42}$ found mothers preferred to talk with friends or family. However, pediatricians who listen well and whom the mother trusts were important factors for creating an environment where the depression discussion could occur. These themes are echoed in the DV literature as critical factors to creating a clinician-patient relationship where DV disclosure can occur. ${ }^{43}$ This is also supported by the qualitative data in this study. The important point here is that clinicians must create a trusting relationship with patients, know how to communicate, and how to listen to discuss sensitive issues, including DV.

The sensitivity of DV to Latina mothers may be explained by a variety of cultural issues that may change with acculturation. Other qualitative work on DV in the Latina community suggest that "machismo," tolerance for abuse in intimate relationships, maintaining privacy, and family loyalty are also barriers to DV disclosure. ${ }^{44}$ Some of these cultural characteristics may explain the increased discomfort of Latinas both alone and with their children in our study. Due to these issues, as culturally competent care guidelines encourage, clinicians should refrain from using family members to translate discussions about sensitive issues, including DV. ${ }^{45}$ 
The fact that this sample of mothers with DV experience $(\mathrm{n}=78)$ did not express any difference in comfort with screening either alone or in front of the children than those with no DV experience is noteworthy. Other work suggests that creating an environment with posters and brochures about DV helps to normalize the issue as well as reassuring patients that the inquiry is part of the routine for everyone. . $6,27,46,47$

Participants reported both positive and negative responses to the $5 \mathrm{DV}$ questions. This suggests that there may not be a perfect question for face-to-face screening. Instead it may be the manner of asking - caring and listening, tailoring questions specific to the patient's situation, having a conversation. For both the patient alone, and with her children, moving from general to specific may be the most comfortable progression. Creating a supportive and trusting environment and relationship may be the key points to verbal screening for sensitive issues. These are also key components for good clinician communication skills.

However, participants emphasized several factors when asking about DV in front of the children that have been identified in other studies. First, as Dowd et $\mathrm{al}^{48}$ found in their study about screening for DV in the pediatric emergency department, managing the child's health issues, why they came to the clinic/hospital, and relating DV to the health of the child were important. Second, mothers suggested that they might take action because it affects the children, steps that they may not take for themselves. We found this in interviews with mothers who had sought assistance for DV in shelters or support groups. ${ }^{49}$ As one participant stated, "there is nothing nearer and dearer to my heart. .. than my children." By helping a mother understand how DV impacts the health of her children in a nonblaming manner, she may be empowered to take steps toward safety that would benefit both her and the children. Finally, participants talked about the importance of paying attention to nonverbal clues and hints. Levinson et $\mathrm{al}^{50}$ found that patients are indirect about sharing psychosocial information with clinicians. Other work demonstrated that patients often give hints about DV, as if testing the water to see what the clinician's response might be. ${ }^{49}$ This may be especially true when the children are present.

There are several limitations to this study. First, this was a convenience sample in a non-medical setting and may not be generalizable to primary care. We purposefully sampled mothers in the community with a child between 3 and 12 years old, an age when well-child checks or school physicals are done and when children would potentially be cognizant of clinician-parent discussion. We thought that a community sample of mothers better addressed the issues about comfort about sensitive issues. Second, due to our recruitment strategy, participants who thought that they might not be comfortable discussing sensitive issues may have been less likely to participate. This may bias our results toward a higher level of comfort. Third, qualitative interviews were limited to the first 40 participants. This did not include Latina women because of limited funds to transcribe and analyze transcripts in Spanish. The Latina sample of women was small $(n=46)$, and although diverse, our findings may not be generalizable to all Latina women. The 40 mothers interviewed were demographically different from the entire sample. In addition, the percentage of women who reported "experience with DV" may be inaccurate due to the wording of the questions and the fact that a standard measure was not used. Finally, both male and female graduate student research assistants collected the data. One study suggests that patients may be more comfortable with gender-matched researchers. ${ }^{51}$ However, research assistants were trained and shadowed until they were competent in conducting sensitive interviews.

Despite these limitations, this is one of the first studies to explore the issue of women's comfort about sensitive issue screening, including DV, both alone and in front of the children. Although accuracy is sacrificed with the general nature of these questions, ${ }^{23,52,53}$ mothers' increased comfort with the less graphic nature of these DV questions (over 94\% when questioned alone) suggests that the questions could be used as an icebreaker or introductory question when a woman is alone or when her children are present. As suggested in the qualitative data, if a clinician gets any hint of a mother's discomfort or inconclusive response, then further questioning with more graphic questions should be done without the children.

\section{References}

1. Campbell J. Health consequences of intimate partner violence. Lancet 2002;359:1331-6.

2. Golding J. Intimate partner violence as a risk factor 
for mental disorders: a meta-analysis. J Fam Violence. 1999; 14:99-132.

3. Edleson J. Children's witnessing of adult domestic violence. J Interpers Violence 1999;14:839-70.

4. Kitzmann K, Gaylord N, Holt A, Kenny E. Child witness to domestic violence: a meta-analytic review. J Consult Clin Psychol. 2003;71:339-52.

5. Koenen K, Moffitt T, Caspi A, Taylor A, Purcell S. Domestic violence is associated with environmental suppression of IQ in young children. Dev Psychopathol 2003;15:297-311.

6. US Preventive Services Task Force. Screening for family and intimate partner violence: recommendation statement. Ann Intern Med. 2004;140:382-6.

7. Ramsay J, Richardson J, Carter Y, Davidson L, Feder G. Should health professionals screen women for domestic violence? Systematic review. BMJ 2002; 325:314-8.

8. Wathen C, MacMillan H. Interventions for violence against women: scientific review. JAMA 2003;289: 589-600; e1-e10.

9. American College of Obstetricians and Gynecologists. Domestic violence: Educational bulletin. Washington (DC):1999;1-9.

10. Committee on Child Abuse and Neglect, American Academy of Pediatrics. The role of pediatrician in recognizing and intervening on behalf of abused women. Pediatrics 1998;101:1091-2.

11. American College of Physicians. Domestic violence: Position paper of the American College of Physicians. Philadelphia PA: March 3, 1986.

12. American Medical Association. American Medical Association diagnostic and treatment guidelines for domestic violence. Arch Fam Med 1992;1:39-47.

13. Council on Scientific Affairs, AMA. Violence against women: relevance for medical practitioners. JAMA 1992;267:3184-9.

14. Ferris L. Intimate partner violence. BMJ 2004;328: 595-6.

15. Lachs M. Screening for family violence: what's an evidence-based doctor to do? Ann Intern Med 2004; 140:399-400.

16. Rhodes $\mathrm{K}$, Levinson $W$. Interventions for intimate partner violence against women: clinical applications. JAMA 2003;289:601-5.

17. Nicolaidis C. Screening for family and intimate partner violence [Letter to the Editor]. Ann Intern Med 2004;141:81-2.

18. Nelson JC, Johnston C. Screening for family and intimate partner violence [Letter to the Editor]. Ann Intern Med 2004;141:81.

19. Brown J, Lent B, Schmidt G, Sas G. Application of the woman abuse screening tool (WAST) and WAST-short in the family practice setting. J Fam Pract 2000;49:896-903.

20. Sherin K, Sinacore J, Li X, Zitter R, Shakil A. HITS:
A short domestic violence screening tool for use in a family practice setting. Fam Med 1998;30:508-12.

21. Coker A, Pope B, Smith P, Sanderson M, Hussey J. Assessment of clinical partner violence screening tools. JAMWA 2001;56:19-23.

22. McFarlane J, Parker B. Preventing abuse during pregnancy: an assessment and intervention protocol. MCN Am J Matern Child Nurs 1994;19:321-4.

23. Feldhaus K, Koziol-McLain J, Amsbury H, Norton I, Lowenstein S, Abbott J. Accuracy of 3 brief screening questions for detecting partner violence in the emergency department. JAMA 1997;277: 1357-61.

24. Paranjape A, Liebschutz J. STaT: a three question screen for intimate partner violence. J Womens Health 2003;12:233-40.

25. Brown JB, Lent B, Brett PJ, Sas G, Pederson LL. Development of the woman abuse screening tool for use in family practice. Fam Med 1996;28:422-8.

26. Zink T. Should children be in the room when mom is screened for partner violence. J Fam Pract 2000; 49:130-6.

27. Zink T, Jacobson J, Elder N. Screening for domestic violence when the children are present: the victim's perspective. J Interpers Violence 2003;18:872-90.

28. Williams R, Vinson D. Validation of a single screening question for problem drinking. J Fam Pract 2001;50:307-12.

29. Addiction Research Foundation. Diagnosis and treatment of drug abuse in family practice: drug abuse screening test (DAST-10).

30. Gerbert B, Bronstone A, McPhee S, Pantilat S, Allerton M. Development and testing of an HIV-risk screening instrument for use in health care settings. Am J Prev Med 1998;15:103-13.

31. Gribble J, Miller H, Rogers S, Turner C. Interview mode and measurement of sexual behaviors: methodological issues. J Sex Res 1999;36:16-24.

32. Kemper K. Self-administered questionnaire for structured psychosocial screening in pediatrics. Pediatrics 1992;89:433-6.

33. Burnam M, Wells K, Leake B, Landsverk J. Development of a brief screening instrument for detecting depressive disorders. Med Care 1988;26:775-89.

34. Denzin NK, Lincoln YL. Collecting and interpreting qualitative materials. Thousand Oaks (CA): Sage Publications, Inc. 1998.

35. Agresti A. An introduction to categorical data analysis. New York: John Wiley \& Sons; 1996.

36. Tjaden P, Thoennes N. Prevalence, incidence and consequences of violence against women: Findings from the national violence against women survey. Washington (DC): US Department of Justice. 1998.

37. Smith PH, Thornton GE, DeVellis R, Earp J, Coker AL. A population-based study of the prevalence and distinctiveness of battering, physical assault and sex- 
ual assault in intimate relationships. Violence Against Women. 2002;8:1208-32.

38. Borkan J. Immersion/crystallization. In: Crabtree B, Miller W, eds. Doing qualitative research. 2nd Ed. Thousand Oaks (CA): Sage Publications Inc. 1999. p. 179-94.

39. Fortenberry JD. The effects of stigma on genital herpes care-seeking behaviors. Herpes 2004;11: 8-11.

40. Dixon-Woods M, Stokes T, Young B, et al. Choosing and using services for sexual health: a qualitative study of women's views. Sex Transm Infect 2001;77: 305-6.

41. Baik SU, Bowers BJ, Oakley LD, Susman JL. The recognition of depression: the primary care clinician's perspective. Ann Fam Med 2005;3:31-7.

42. Heneghan AM, Mercer M, DeLeone NS. Will mothers discuss parenting stress and depressive symptoms with their child's pediatrician? Pediatrics 2004;113:460-7.

43. Gerbert B, Caspers N, Bronstone A, Moe J, Abercrombie P. A qualitative analysis of how physicians with expertise in domestic violence approach the identification of victims. Ann Intern Med 1999;131: $578-84$.

44. Lewis MJ, West B, Bautista L, Greenberg AM, Done-Perez I. Perceptions of service providers and community members on intimate partner violence within a Latino community. Health Educ Behav 2005;32:69-83.

45. Office of Minority Health. Assuring cultural competence in health care: recommendations for national standards and an outcomes-focused research agenda.
US Department of Health and Human Services. March 2001.

46. Gerbert B, Abercrombie P, Caspers N, Love C, Bronstone A. How health care providers help battered women: the survivor's perspective. Women Health 1999;29:115-35.

47. Zink T, Jacobson J, Elder N. Medical management of intimate partner violence considering the stages of change: precontemplation and contemplation. Ann Fam Med 2004;2:231-9.

48. Dowd M, Kennedy C, Knapp J, Stallbaumer-Rouyer J. Mothers' and health care providers' perspectives on screening for intimate partner violence in a pediatric emergency department. Arch Pediatr Adolesc Med. 2002;156:794-9.

49. Zink T, Elder N, Jacobson J. Intimate partner violence: how the children affect the mother/victim's process. Arch Pediatr Adolesc Med 2003;157:58792.

50. Levinson W, Gorawara-Bhat R, Lamb J. A study of patient clues and physician responses in primary care and surgical settings. JAMA 2000;284:1021-7.

51. Berg JA. Gaining access to under-researched populations in women's health research. Health Care Women Int 1999;20:237-43.

52. Peralta R, Fleming M. Screening for intimate partner violence in a primary care setting: The validity of "feeling safe at home" and prevalence results. J Am Board Fam Pract 2003;16:525-532.

53. Zink T, Levin L, Putnam F, Beckstrom A. The accuracy of five general domestic violence screening questions. Clin Pediatr In press 2006. 